\title{
Urban infrastructure development in a global knowledge-based economy
}

\author{
Evelina Sycheva ${ }^{1, *}$, Artur Budagov ${ }^{2}$ and Andrey Novikov ${ }^{3}$ \\ ${ }^{1}$ Saint-Petersburg Polytechnic University of Peter the Great "Industrial Management Institute, \\ economy and trade, 195251, Saint Petersburg, Russia. \\ ${ }^{2}$ State University of Aerospace Instrumentation, Director of the Institute of Enterprinership \\ Technologies, 190000, Saint Petersburg, Russia. \\ ${ }^{3}$ SPBU, Department of Economic Theory and Economic Policy, 191194, Saint Petersburg, Russia.
}

\begin{abstract}
The challenge of globalization process is the emergence of "new economy" in which the knowledge-based economy is of great importance. The factor of the knowledge-based economy is growing under the influence of scientific and technological revolution and involvement in globalization. The article analyzes the relationship of changingtechnological paradigms of social-economic development with sustainable development of urban infrastructure. The challengesof the Sixth (according to the classification of S. Yu. Glaziev)paradigm of the technological revolution with widespread introduction of digitalizationare specified. Up-to-date aspects of management of urban infrastructure development with use of "Smart City"advanced intellectual information technologies are considered. The study provides a reinterpretation of modern methods of management of urban infrastructure development in connection with the emergence of digital information and communication technologies. Knowledge management, including human capital assets management, representing the creative potential of people, plays an important role for "smart management". It is proved that intellectual resources have greater value and competitive advantages than material resources. It is justified that with the development of globalization and digitalization of society, sustainable development of urban infrastructure is based on the use of knowledge-based capital.
\end{abstract}

\section{Introduction}

The idea of technical and economic development as a process of changing technological paradigms allows to measure the processes of long-term economic development. The results of these measurements using the materials of specific historical empirical studies of the world and Russian economy revealed the formation and change of five technological paradigms, as well as provided an insight into the structure of the new sixth technological paradigm, the development of which will determine economic growth in the next 2-3 decades (Fig.1) [1].

\footnotetext{
* Corresponding author: sovmu4@mail.ru
} 


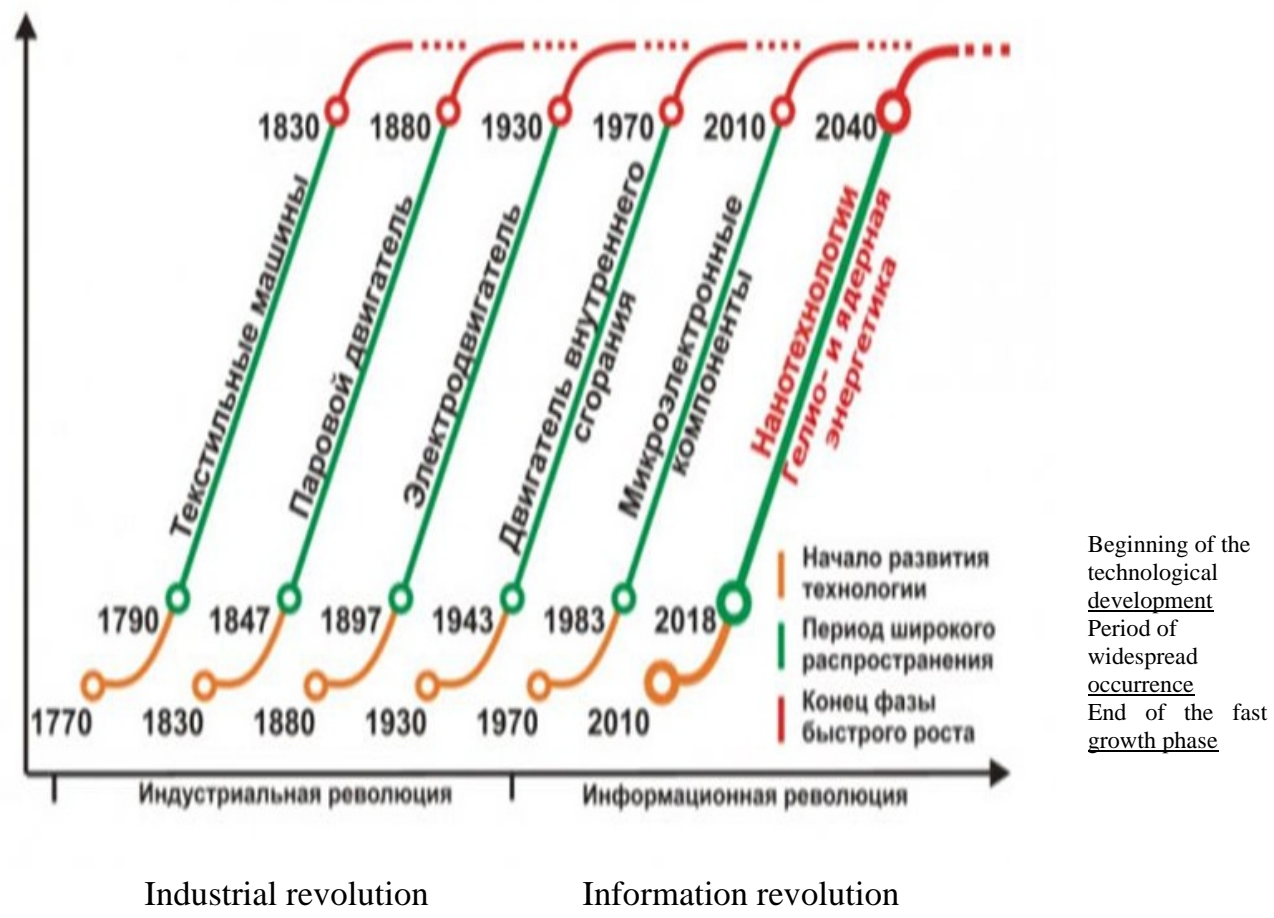

Fig. 1. Change of technological paradigms in the course of modern economic development

1770 - 1790 - Textile machinery - 1830

1830 - 1847 - Steam engine - 1880

1880 - 1897 - Electric engine - 1930

1930 - 1943 - Internal combustion engine -1970

1970 - 1983 - Microelectronic components - 2010

2010 - 2018 - Nanotechnology, Solar-power and nuclear energy engineering - 2040

At the beginning of the industrial revolution, each new technological paradigm uses the existing transport infrastructure and energy sources in its development. In the process of change oftechnological paradigmsthe structure of demand for scientific discoveries and inventions changes. With the exhaustion of the growth opportunities in each technological paradigm, there is a need for fundamentally new technologies, the competitive selection of which forms the basis of new technological paths.

It is generally believed that the information revolutionstarts at the end of the third and at the beginning of the fourth technological paradigms with the emergence of electronic computing machines (ECM) which operate with numbers without human intervention by generating and transmitting information. People only programthem and assign tasks. And with the invention of artificial intelligence ECMbegin to set and solve problems independently without human intervention. Since the early 1980smicroelectronics has become a key factor in the fifth technological paradigm. With the invention of computers and the Internet global information and communication networks emerge in all areas of management, in research and consumer-related sphereand a significant improvement in the 
quality of lifeis provided. Nowadays, a new sixth technological paradigm is coming into force, the transition to which is carried out through the next technological revolution, which radically increases the efficiency of the main directions of economic development - the use of nanotechnology in all areas, including, in particular, urban infrastructure.

The aim of the research is to study the problems and discuss the prospects of urban infrastructure development in the context of digital transformation.

\section{Digital transformation of urban infrastructure-innovative solution for sustainable development based on the knowledge- based economy}

The introduction of digital information and communication technologies has led to a reinterpretation of modern methods of management of urban infrastructure development. Ideally, it is the transition to an integrated urban system that would meet the needs of residents, businesses and authorities, as well as ensure the effective integration and development of individual elements of urban infrastructure and strengthen competitiveness. Conceptually, this transition is interpreted by the term "Smart City".

The first mention of the term "Smart City" appeared in the early 2000s [2]. Since then, at the content level, the concept has undergone some changes, but has not lost its relevance. In terms of methodology, there are three stages that take place in the formation of smart cities. The concept of "Smart City" originally described the ways of using IT-infrastructure to create a virtual city space in the information society [3, 4]. At the second stage, the smart city was mainly associated with the strengthening of the role of intelligent technologies in improving the efficiency of urban development [5]. Finally, it is now increasingly common to talk about a smart sustainable city in which information and communication technologies, on the one hand, are used to improve the quality of life, the efficiency of the city functioning and the provision of urban services, and on the other hand -meet the needs of present and future generations, without affecting the economic, social and environmental components of the city [6].

Russian experience in the development of smart cities cannot be attributed to the advanced one. Based on globalization factors and modernization opportunities, the modernization of Russian cities, according to Western experts, can be correlated to the "catch-up" model of modernization [7]. In the published international rankings, Moscow is ranked $77^{\text {th }}$, St. Petersburg is $88^{\text {th }}$, and only one Russian company appears among the key participants in the smart city technologies market - Kaspersky Lab, that provides solutions in the field of cybersecurity [8]. Nevertheless, the tasks of innovative urban development were assigned to the priority areas of activity in the Decree of the President of the Russian Federation V. V. Putin No. 204 dated May 7, 2018 "On national goals and strategic objectives of the development of the Russian Federation for the period up to 2024".

Smart city systems provide collection, storage and processing of the received information, allow to predict the development of situations and behaviour of individual infrastructure facilities, as well as the city as a whole. The use of innovative information and communication technologies leads to the optimization of urban processes, and this optimization is achieved by combining various elements and participants in an interactive intelligent system.

Smart urban infrastructure brings together specific technological solutions in certain areas of intellectualization of urban life: smart home, smart transport, smart energy, smart healthcare, smart waste management and environmental protection, etc.

The concept of "Smart city" contributes to the emergence and the development of new ("smart") forms of economic activity, including digital economy, knowledge-based 
economy, network economy. By providing access to participants in urban processes, it is possible to develop the production of electronic goods and service activities - new forms of electronic business and e-commerce appear. At the same time, in the gross regional product of the city, a significant share is composed by the results of intellectual labour and innovative activity, which forms the factors for the transition to the knowledge-based economy. Japanese researcher T. Sakaya believes that the driving forces of the new economy are the values created by knowledge, and she calls the modern society as the one based on the values created by knowledge [9]. The value of knowledge manifests itself as a source of ideas and ways to implement them. It is proved that the main source of the knowledge-based economy is the creative potential of people. A characteristic feature of the knowledge-based economy is that increasing importance is attached to the individual's ability to generate and implement innovation. Operatinga large amount of data represented by digitalization, specialists should have the knowledge and ability to choose to implement only those innovations that have the most positive social and environmental impact. Analysis of a large amount of data allows to make decisions at a qualitatively new level with the corresponding economic effect. For example, according to the OECD (Organization for Economic Cooperation and Development) research on Russia No.252 dated June 7, 2016,by 2020the economic effect from the introduction of "Internet of things"technologies, which allow to identify and combine real and virtual objectsinto a single information space on the basis of common standards and communication protocols, can reach 2 trillion $\$$. According to other estimations, the world economy can save more than 5 trillion \$only byuse of autopilot technology in urban "smart transport".

Smart-technologiestransform all spheres of the economy, including knowledge-based economy, in the direction of the development of Smart-society. Based on historical experience, in order to accelerate social-economic development each state has to introduce new or change old institutions of society under the influence of changing geographic information factors [10]. In the era of digitalization, changing the structure of society means the emergence of new types of employment and professions, the introduction of artificial intelligence and the Internet of things in all spheres of human activity, the development of digital literacy, culture and forms of communication, etc. [11]. The development of the digital economy is inextricably linked to the development of the knowledge-based economy. At the same time, not only technical means and information technologieswill bedrivers of its growth, but also knowledge and people possessing this knowledge [12]. An important role in the formation of a Smart society is played by the necessary transformation of technologies in education. Education is necessary for the formation of the future society and the development of human capital assets. The new model of development and use of human capital assetsis based on importance of highly qualified personnel [13]. Training and retraining of professionals of new qualifications is necessary. Recentlycoaching has been increasingly used as a unique systematic approach to continuous education of employees [14]. In the existing studies, coaching as a new method of development and training is defined as the most effective tool for achieving any goals in any sphere of activity.

The competence approach is the methodological basis of modern educational programs. For future specialists who aim to develop and implement the concept of "smart city", it is necessary to form competences focused on the development of skills in the field of strategic management [15]. And the problem at the present stage is not to acquire new knowledge in individual sections of management, but to form a new type of manager [16]. Knowledge management, including human capital assets management, plays an important role in "smart management". Some experts explain the transformation of forms of human resources management as the convergence of the two paths of management and human resources development, as well as suggest the introduction of talent management focused on increasing human capital assets $[17,18]$. A new approach to human resources 
management is associated with entering the knowledge-based economy [19]. And knowledge, unlike material resources, is inexhaustible and, it seems fair to say, gives us new types of energy and new materials. Human capital assets management is based on the approach according to which human resources, unlike other economic resources, are considered as the highest value and a source of competitive advantages. According to Western experts, human resources are the equivalent of material values obtained by the world economy [20]. The value of human resources is determined by the level of education, skill, qualification and culture. The importance of human capital assets, competences of specialists and managers of all ranks is now significantly increasing [21].

In connection with the digital revolution, the possibility of some social problems should also be noted. These include the growth of unemployment for which it is necessary to provide for the retraining of workers released from the outdated technological paradigm to a new profession in demand. Here, state assistance is needed to restructure the education system to meet the demand for new professions and subsidize retraining programs [22].

Management development is manifested in various forms, in particular in strategic planning, development of organizational culture, organizational development, monitoring, and specific management technologies such as business planning, quality control circles etc. The main form of implementation of management development is strategic planning. The strategy of development of digital economy sectors of the urban economy can be represented in various forms: business plan, strategic maps, etc., which will be directly connected with a new level of digitization. The quality of strategic documents is becoming increasingly important due to changes in the institutional framework after the adoption of the Federal Law "On strategic planning in the Russian Federation" [23]. On the basis of the existing infrastructure of individual sectors of the municipal economy, local business projects aimed at the introduction of intelligent technologies are created, which then are combined into a system. As one of the final stages of strategic planning (in terms of strategy detail), business planning allows to determine the resources required to achieve goals and to define a balanced scorecard that can be used to carry out operational management and evaluation of the implementation of the strategy at its individual stages [24].

In our opinion, the strategic directions and goals of the city development taking into account digitalization are the following:

- human capital assets development;

- improving the quality of the urban environment;

- ensuring sustainable economic growth;

- ensuring effective management and development of civil society.

Achieving these effects leads to the main goal: improving the quality of life in cities through the introduction of innovative information and communication technologies to the development of the urban environment.

\section{Conclusions}

Thus, as a result of the conducted research it is possible to draw the following conclusions:

1. The challenge of globalization is the emergence of a "new economy" in which the knowledge-based economy is of great importance.

2. The knowledge-based economy is growing under the influence of the scientific and technological revolution and globalization.

3. Now at the point of the transition to the sixth paradigm (according to S. Yu. Glaziev's classification) of technological revolution,in the processof modern social and economic development,digitalization has captured practically all types of activity, including the sphere of urban infrastructure. 
4. Digitalization of urban infrastructure is difficult to imagine without the idea of "Smart City", which implies the creation of a modern smart efficient city that adapts to innovative information and communication technologies and the way of life of modern people.

5. The smart city approach is based on a deep understanding of the role of social connections and human capital assets in urban development.

6. The development of digital information and communication technologies has led to the reinterpretation of modern methods of urban infrastructure management.

Implementation of the "smart city" model imposes new requirements to the conditions of training of qualified specialists. The new level of functioning of separate infrastructures of the city imposes the increased requirements to the efficiency of work with labour and human resources.

\section{References}

1. S.Yu. Glaziev. Velikaya tsifrovaya economica. [Great digital technology]Authors report of S. Glaziev to the Izborsk club.September 4, (2017).

2. D.Sikora-Fernandez, D. Stawasz. The Concept Of Smart City In The Theory And Practice Of Urban Development Management. Romanian Journal of Regional Science 10, 81-99 (2016).

3. T. Ishida, K. Isbister. Digital Cities: Technologies, experiences, and future perspectives. (Springer-Verlag, Berlin, 2000).

4. N. Komninos. The Age of Intelligent Cities. Smart environments and innovation-for-all strategies. (Routledge, New York, 2015).

5. A. Van der Meer, W. Van Winden. E-governance in Cities: A Comparison of Urban Information and Communication Technology Policies. Regional Studies 37, 407-419 (2003).

6. B. Fernando, V. Jaume. Rethinking the Effects of Financial Globalization. The Quarterly Journal of Economics 131, 1497-1542 (2016).

7. F. Armin, A. Becker, T. Dohmen, B. Enke, D. Huffman, Uwe Sunde Global Evidence on Economic Preferences. The Quarterly Journal of Economics 133, 1645-1692 (2018).

8. G. Padrói Miquel, The Control of Politicians in Divided Societies: The Politics of Fear. The Review of Economic Studies 74, 1259-1274 (2007).

9. T. Sakaya. Novaya postindustrialnaya volna na Zapade: Antologiya. Stoimost', sozdavaemaya znaniyami, ili Istoriya buduschego. [New postindustrial wave in the West: Anthology. Price created by knowledge or History of the future]. 337. (1999).

10. F.J. Bierbrauer, P.C. Boyer, Efficiency, Welfare, and Political Competition. The Quarterly Journal of Economics 131, 461-518 (2016).

11. P. Parviainen, M. Tihinen, J. Kaariainen, S. Teppola. Tackling the digitalization challenge: how to benefit from digitalization in practice. International Journal of Information Systems and Project Management 5, 63-77 (2017).

12. C.N. Noussair, S.T. Trautmann, G. Van de Kuilen. Higher Order Risk Attitudes, Demographics, and Financial Decisions. The Review of Economic Studies 81, 325-355 (2014)

13. M.K. Chan, Welfare Dependence and Self-Control: An Empirical Analysis. The Review of Economic Studies 84, 1379-1423 (2014) 
14. S. Guthmuller, F. Jusot, J. Wittwer, Improving Takeup of Health Insurance Program: A Social Experiment in France. Journal of Human Resources, 167-194 (2014)

15. P. Martin, T. Mayer, Thoenig. Make Trade Not War? The Review of Economic Studies 75, 865-900 (2008)

16. V. Yu. Mikhina, M. A. Kuznetsova, E. V. Sycheva. Economicsafety: legal, economic, ecological aspects: collection of scientific papers of the International research to practice. Some theoretical particularities of the quality management 2, 160-163. (2017).

17. F. L. Cooke, A. Veen, G. Wood, What do we know about cross-country comparative studies in HRM? A critical review of literature in the period of 2000-2014. The International Journal of Human Resource Management 28, 196-233 (2017).

18. A.J. Glaister, G. Karacay, M. Demirbag, E. Tatoglu, HRM and performance - The role of talent management as a transmission mechanism in an emerging market context. Human Resource Management Journal 28, 148-166 (2018)

19. M. Adamova, R. Krninska. The influence corporate culture of knowledge economy on financial performance of small and medium-sized enterprises. Proceedings of the $16^{\text {th }}$ International Scientific Conference of Globalization and its Socio-Economic Consequences. Rajecke Teplice, Slovakia (2016).

20. D. Berger, V. Guerrieri, G. Lorenzoni, J. Vavra, House Prices and Consumer Spending. The Review of Economic Studies 85, 1502-1542 (2018).

21. E.V. Sycheva, A.S. Budagov, Anti-crisis management under conditions of globalization. Proceedings of the 18th International Scientific Conference on Globalization and its Socio-Economic Consequences. Rajecke Teplice, Slovakia (2018).

22. E. V. Sycheva. Social anthropology of the city: cultural, social and economic space. New view on the future of urban infrastructure. Saint Petersburg, Russia (2019).

23. R.A. Lugovskoy, E.V. Sycheva, Neobkhodimost' formirovaniya mekhanizmov otsenki effektivnosti gosudarstvennogo strategicheskogo planirovaniya. [Necessity of formation of evaluation mechanisms of the state strategic planning]. International technical and economic magazine 5, 7-13 (2014).

24. F. Boffa, A. Piolatto, A. Giacomo, Ponzetto Political Centralization and Government Accountability. The Quarterly Journal of Economics 131, 381-422 (2016) 